\title{
Intersectionality and the social meanings of variation: Class, ethnicity, and social practice
}

\author{
S A M K I R K H A M \\ Department of Linguistics and English Language, County South, Lancaster \\ University Lancaster LA1 4YL, United Kingdom \\ s.kirkham@lancaster.ac.uk
}

\section{A B S T R A C T}

This article examines how the social meanings of phonetic variation in a British adolescent community are influenced by a complex relationship between ethnicity, social class, and social practice. I focus on the realisation of the HAPPY vowel in Sheffield English, which is reported to be a lax variant $[\ddot{\varepsilon}]$ amongst working-class speakers but is undergoing change towards a tense variant [i] amongst middle-class speakers. I analyse the acoustic realisation of this vowel across four female communities of practice in a multiethnic secondary school and find that the variable's community-wide associations of social class are projected onto the ethnographic category of school orientation, which I suggest is a more local interpretation of class relations. Ethnographic evidence and discourse analysis reveal that local meanings of the HAPPY vowel vary further within distinctive community of practice styles, which is the result of how ethnicity and social class intersect in structuring local social practices. (Intersectionality, indexicality, social meaning, identity, ethnicity, social class)*

\section{N T R O D U C T I O N}

Social categorisation is central to the study of sociolinguistic variation. Early research uncovered structured patterns of linguistic differentiation within urban communities, foregrounding the pervasiveness of social categorisation and its influence on linguistic variation (e.g. Labov 1966, 1972; Trudgill 1974). One subsequent strand of research has sought to further understand the local meanings of these social categories, with a focus on how such an understanding can inform our knowledge of the social meanings of linguistic variation and how variation is used for identity construction (Eckert 2012). A promising development in this line of inquiry is an increased awareness of intersectionality - the idea that multiple axes of social differentiation intersect in producing systems of identification within a social matrix (Crenshaw 1991; Eckert \& McConnell-Ginet 1992; McCall 2005; Levon 2011; Eckert 2014). A view of identity as intersectional holds that the meanings of social categories (e.g. gender) may vary as a function (http://creativecommons.org/licenses/by/4.0/), which permits unrestricted re-use, distribution, and reproduction in any medium, provided the original work is properly cited. 
of how they intersect with other aspects of a person's identity (e.g. ethnicity, class, sexuality).

Previous research has outlined the difficulties of developing a systematic methodology for tracing how social categories intersect. For instance, Levon (2011) asks whether intersections represent 'vectors of influence', whereby being 'black' influences being 'female' in a discrete way, or whether categories are 'inextricable and interdependent, such that "black woman" represents an indivisible unit?' (Levon 2011:70). In this article I suggest that one approach is to situate intersectionality in terms of communities of practice. A community of practice (CofP) is 'an aggregate of people who come together around mutual engagement in an endeavour' (Eckert \& McConnell-Ginet 1992:464), where group membership is defined by joint engagement in shared social practices (Lave \& Wenger 1991). CofPs are claimed to represent the site at which individuals experience social categories in everyday life (Eckert \& McConnell-Ginet 1992) and should, therefore, capture people's lived experience of a range of intersecting social categories and their concomitant influence on social practice. A focus on social practice has already led to considerable advances in variationists' understanding of social categories such as gender (Eckert \& McConnell-Ginet 1992; Cheshire 2002), age (Eckert 2000; Bucholtz 2002; Kirkham \& Moore 2013), and ethnicity (Eckert 2008a; Mendoza-Denton 2008; Benor 2010; Alam \& StuartSmith 2011).

Another category, social class, has featured prominently since the inception of the variationist paradigm (e.g. Labov 1966, 1972; Trudgill 1974; Bourdieu 1977; Rickford 1986; Milroy \& Milroy 1992; Dodsworth 2009; Ash 2013). A number of scholars, however, have lamented the comparable lack of socially sensitive accounts of class (Halliday 1990; Rampton 2010; Block 2014), with Hymes (1996:73) noting that class is often treated as a matter of 'statistical difference' rather than a 'lived reality'. It is worth noting that Labov (1966) does make a number of allusions to the cultural, variable, and nondeterministic nature of class, but recent research has sought to address this gap in more detail, such as Eckert's (2000) analysis of how Jock and Burnout high school cultures represent partial reinterpretations of wider class relations. Snell (2010) also shows that there exists a complex relationship between stance, indexicality, and linguistic variation in her study of class-associated variation (see also Rampton 2006). There remains further scope for development, however. For example, being 'workingclass' is likely to structure life experiences differently depending on whether one identifies as ethnically 'Black' or 'White' (e.g. Rollock, Gillborn, Vincent, \& Ball 2015). Class and ethnicity are particularly interesting in this regard, as different generations may have substantially different experiences of racialised class structures (Platt 2005), which can impact upon how they use linguistic variation for identity work (e.g. Sharma \& Sankaran 2011). It is therefore imperative to consider the ways in which ethnicity itself is structured as a class relation (Rampton 2010:2). Examining intersections between class and ethnicity is likely to further enrich our 
understanding of these social categories, as well as how patterns of social organisation are reflected in - and indexed by — patterns of linguistic variation.

This article reports how phonetic variation is used to index social meanings and identities in a multiethnic secondary school in Sheffield, a city in the north of England. In particular, I explore how these meanings relate to local and intersecting meanings of class and ethnicity and their influence on social practice. To this end, I conceptualise ethnicity and social class as fundamentally relational phenomena, which encompass material conditions and social practices, as well as discourses and ideologies that articulate power relations between groups (Rampton 2006:222; see also Marx 1852/1972; Foucault 1962; Barth 1969; Bourdieu 1984). My analysis focuses on an aspect of sociophonetic variation that is reported to correlate with demographic indices of class within Sheffield: the HAPPY vowel (Wells 1982:166). I show how acoustic variants of HAPPY may be used for indexing social relations that go beyond simple conceptions of class or ethnicity, but which are nonetheless framed by how local meanings of class and ethnicity intersect. As such, this research ties in with a broader enterprise that seeks to understand how variation is used to articulate social meanings and identities (Eckert 2012), with social meaning referring to 'the stances, personal characteristics, and personas indexed through the deployment of linguistic forms in interaction' (Podesva 2011a:234). This perspective provides one way of tracking how linguistic features that correlate with demographic categories may be used to index more local identities and form distinctive styles (e.g. Moore \& Podesva 2009; Podesva 2011b; Eckert 2012).

\section{Social class and variation in the HAPPY vowel}

This study focuses on the realisation of the HAPPY vowel in Sheffield English, which is the word-final unstressed vowel that occurs in words such as happy, silly, and furry (Wells 1982:166). Previous research suggests that working-class speakers in Sheffield (defined in fairly simplistic socioeconomic terms) produce a hyperlax realisation of HAPPY similar to [ $\ddot{\varepsilon}$ ], whereas middle-class speakers are engaged in an ongoing sound change in which this vowel in shifting to a higher and fronter vowel [i] (Stoddart, Upton, \& Widdowson 1999; Beal 2004; Finnegan 2005). This sound change is commonly called 'HAPPY-tensing' (Wells 1982:258) and is well attested across southern (Fabricius 2002; Harrington 2006) and midland (Docherty \& Foulkes 1999:50; Hughes, Trudgill, \& Watt 2005:88; Flynn 2007) dialects of England. The HAPPY vowel is typically reported to be closer to [I] in most northern English varieties (Hughes et al. 2005), but some northern accents, such as Sheffield and Manchester, are reported to have realisations that

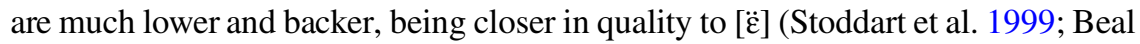
2004).

As mentioned above, previous research notes that lax HAPPY realisations are associated with working-class speakers in Sheffield (Beal 2004; Finnegan 2005), but it is important to stress that 'working-class' in this context typically means 'White 
British working-class'. Rogaly \& Taylor (2009:4) note that this kind of ethnic and class erasure is pervasive in much social research, with ethnically White people typically defined in terms of social class, and minority ethnic people typically defined in terms of ethnic heritage. To my knowledge, there has been no previous research On HAPPY variation in minority ethnic speakers in England, but Heselwood \& McChrystal (2000:50) report that two listeners in their study reported 'lengthening of lax vowels' as a characteristic of Panjabi-accented English in Bradford. The data I report below are from a multiethnic contact situation and I noticed during my fieldwork that some Pakistani and Somali adolescents would often produce hyper-tense realisations of the HAPPY vowel. This points towards a range of HAPPY variation in Sheffield, including the 'traditional' working-class lax variant, a supralocal middle-class tense variant, as well as the use of tense variants by some minority ethnic speakers, which may potentially originate in heritage language influence (see Heselwood \& McChrystal 2000).

Given this context, the HAPPY vowel is an appropriate case study for examining the classed associations of phonetic variation and how they intersect with ethnicity. Indeed, HAPPY was one of the few linguistic features explicitly commented upon in my fieldwork. Take the following episode of discourse produced by one of the girls, Polly, which formed part of a longer interaction about 'chavs' in the school. The word 'chav' is defined in the Oxford English Dictionary Online (2014) as 'a young person of a type characterized by brash and loutish behaviour and the wearing of designer-style clothes (esp. sportswear); usually with connotations of a low social status'. Over the course of my fieldwork, the term chav was frequently used as a derogatory insult, particularly towards White British adolescents from socioeconomically disadvantaged backgrounds who adopted a particular style of speech and dress (see Bennett 2012 for an analysis of the discursive construction of 'chavs' in Britain). 1

1 Sam: how do they speak?

2 (.)

3 Polly: common.

4 Sam: like w- w- what does =

5 Polly: =like they don't say

$6 \quad$ Polly [ $\mathrm{p}^{\mathrm{h}} \mathrm{pti}$ they say Polly [ $\left.\mathrm{p}^{\mathrm{h}} \mathrm{pł} \ddot{\varepsilon}\right]$

Polly's realisation of HAPPY denoted by [ $\ddot{\varepsilon}]$ in line 6 is auditorily hyper-lax and also has a lower acoustic value than any of the nonmock speech tokens in the entire data set (note that the name Polly is a pseudonym for a phonetically similar name). One acoustic measure that captures the quality of the HAPPY vowel is the F2 minus F1 (F2-F1) frequency, with higher values indicating higher and fronter (tenser) vowels and lower values indicate lower and backer (laxer) vowels. The first token denoted by [i] has a F2-F1 value of 11.02 Bark, whereas 
the second token denoted by [ $[\ddot{\varepsilon}]$ has a F2-F1 value of 2.36 Bark. Considering that the overall range for female speakers' productions of HAPPY is 3.92-13.8 Bark (excluding the above tokens), Polly's metalinguistic imitations capture a good deal of the acoustic range involved in this sociophonetic contrast. This episode also points towards some potentially stereotyped meanings for lax realisations of HAPPY in that Polly positions the lax variant to be characteristic of people who are 'chavs' and sound 'common', thus linking a style of dress and speech to the essentialist 'chav' stereotype. By contrast, the tense variant is presumably not 'chav'. This may represent a more local reinterpretation of the wider class associations reported by Beal (2004), which relies on invoking a set of stylistic and cultural stereotypes that are fundamentally classed in nature.

The rest of this article reports a phonetic, ethnographic, and discourse analysis of HAPPY realisation amongst a group of adolescents in a multiethnic secondary school. The next section reports the details of an ethnographic study of communities of practice in a multiethnic school in Sheffield. Then I report a quantitative phonetic analysis that proposes that the community-wide classed associations of HAPPY realisation are subjected to fractal recursivity (Irvine \& Gal 2000:38). This involves the projection of oppositions on one level (such as social class) onto another level (such as local school-based identities). Finally, I analyse how local meanings of HAPPY vary in subtle ways across communities of practice and in their discourse usage, which I argue is indicative of how social practice, ethnicity, and class interact with other. In doing so, I suggest that the social meanings of HAPPY variation are multifaceted, influenced by both community-wide associations (such as social class) and context-specific social dynamics (such as school orientation and community of practice membership).

\section{T H E S T U D Y}

The data for this study are drawn from an ethnographic study of a Sheffield secondary school, which I call Ashton Valley School. This study was carried out over a period of fifteen months in 2010-2011 with adolescents aged between thirteen and fifteen years old. Ashton Valley School is based in a very affluent suburb of Sheffield, but it admits students from across the city, resulting in a social mix that is considerably more diverse than the surrounding neighbourhood. Note that the initial outline below focuses on official local authority statistics and thus represents a more 'etic' perspective than the more 'emic' one that is adopted throughout the rest of this article. The neighbourhood in which the school is located has a minority ethnic population of $11.1 \%$, whereas the school has a minority ethnic population of 33\%. While it is more difficult to compare class diversity, the school had fewer students eligible for free school meals, a common proxy for socioeconomic disadvantage, than the average for Sheffield schools (13.5\% compared to $18.2 \%$ ). However, academic attainment for 'disadvantaged pupils' was considerably worse at Ashton Valley than the average for Sheffield schools (see Kirkham 2013:55 for 
more details). This paints a picture of Ashton Valley School as more ethnically diverse than socioeconomically diverse, but nonetheless a site at which individuals from a diverse range of neighbourhoods across Sheffield come into contact.

During the ethnographic study, I attended school alongside the adolescents for between two and four days per week over a period of fifteen months. This involved observing students during lessons and break times in order to understand the social structure of the adolescent peer community in the school (see Eckert 2000; Mendoza-Denton 2008; Moore 2010; Lawson 2011; Wagner 2013 amongst others for a similar approach). Out of this process, I identified a number of communities of practice that characterised the peer structure of the year group. For the purposes of analysing speech data, interviews with female and male adolescents were recorded in small self-selected groups within CofPs. In this article, I only focus on the twenty-three female speakers for the purposes of exploring the complex patterns in more detail. Kirkham (2013) found relatively few differences for HAPPY amongst male speakers in this community, except for the robust finding that Somali boys produce much tenser tokens of HAPPY when the vowel is preceded by /1/. A similar finding is also reported and discussed in more detail for the girls in the quantitative analysis below. In addition to this, there was very sharp gender segregation at the time of my fieldwork with no inter-gender CofPs, which further supports focusing on the female speakers separately from the male speakers.

For the purposes of accounting for various social dimensions of variation, information on community of practice membership, self-reported ethnicity, and first language were collected from each speaker. Earlier, I detailed the theoretical background of this study, which is reflected in the use of communities of practice as an analytic tool. As such, the inclusion of other categories in my analysis, such as ethnicity and level of socioeconomic deprivation, may seem at odds with the more 'emic' approach adopted elsewhere in this study. My reasons for including these categories, which are traditionally used in quantitative variationist work, is to examine whether the ethnographic intersection of these categories (community of practice) better explains phonetic variation than these categories alone. Even so, this is done with the caveat that any statistical effects of these demographic categories need to be interpreted in terms of their local meaning within the ethnographic context. With this in mind, the statistical category of 'ethnicity' is operationalised as a categorical variable based on individual self-identification in terms of the UK's Census 2011 categories. The 'level of deprivation' indicator is a holistic quantitative measure of socioeconomic deprivation in Britain, based on data derived from the UK government's 'index of multiple deprivation' statistics. This indicator has three levels that relate the socioeconomic characteristics of each speaker's neighbourhood to citywide averages: (i) significantly higher than average deprivation, (ii) average deprivation, and (iii) significantly lower than average deprivation (see Kirkham 2013:103-104 for further details). I also collected data on bilingualism, including the amount of self-reported heritage language use for all bilingual speakers. 
TABLE 1. Individual speaker information for each community of practice. Level of deprivation refers to whether an individual's postcode is significantly HIGHER than the city average, LOWER than the city average, or AVERAGE (not significantly different from the city average).

\begin{tabular}{lllll}
\hline \hline CofP & Name & Ethnicity & First language & Level of deprivation \\
\hline Ashton & Toni & White British & English & lower \\
girls & Bea & White British & English & lower \\
& Nikki & White/Black Carib. & English & lower \\
& Nasra & Somali & Somali & higher \\
Twilight & Naadiya & Somali & Somali & higher \\
girls & Aisha & Somali & Somali & average \\
& Hishma & Somali & Somali & higher \\
& Izma & Pakistani & Urdu & lower \\
& Salma & Pakistani & Panjabi & higher \\
& Aatifa & Pakistani & Panjabi & higher \\
Parkdale & Kasey & White British & English & higher \\
girls & Claire & White British & English & higher \\
& Alyssa & White/ Black Carib. & English & average \\
& Jada & White/Black Carib. & English & higher \\
& Tammy & White/Black Carib. & English & higher \\
Rebellious \\
girls & Holly & White British & English & lower \\
& Katy & White British & English & higher \\
& Mel & White British & English & lower \\
& Amy & White British & English & lower \\
& Polly & White/Black Carib. & English & lower \\
& Saliha & White/Black Carib. & English & higher \\
& Leila & Pakistani & Urdu & higher \\
& Zara & Bangladeshi & Bengali & higher \\
\hline \hline
\end{tabular}

Table 1 shows individual-level data for the twenty-three female speakers who are included in the phonetic analysis. This includes information on community of practice, speaker ethnicity, and level of deprivation relative to the city average.

Amongst the girls there are four communities of practice, which can be grouped into two 'pro-school' and two 'anti-school' CofPs. These school orientations refer to whether or not a group upholds the school's institutional values and willingly participate in its aims (see Willis 1977; Eckert 1989; Moore 2010 for empirical validation of this approach). The Ashton girls are a pro-school group of middle-class girls from a very affluent neighbourhood in Sheffield, who are predominantly White British but also include some White \& Black Caribbean and Somali girls (note that this is not entirely reflected in Table 1; some of the other White British girls could not be included in the phonetic analysis due to problems with the recording equipment). The Twilight girls are a pro-school group of second-generation Pakistani and Somali girls who all identify as Muslim and named themselves after their love of the popular teen fiction Twilight novels. They are generally from more socioeconomically deprived neighbourhoods (see Table 1), but are educationally aspirational and 
highly pro-school. The Parkdale girls are an anti-school group of White British and White \& Black Caribbean girls from a more deprived neighbourhood in Sheffield. They demonstrate a strong rejection of the school's institutional authority and are often abusive towards teachers and other students. Finally, the Rebellious girls are an anti-school group who are more ethnically and socioeconomically mixed. They maintain an urban 'street' orientation and exhibit a desire to see themselves as equals with school authority. While the Parkdale and Rebellious girls are both anti-school, they are differentiated in terms of the nature of their anti-schoolness: the Parkdale girls reject the school's authority outright, whereas the Rebellious instead express a desire to renegotiate the school-student relationship on terms that are more favourable to them. They often do so by invoking discourses of reciprocal 'respect', which previous research suggests is typical amongst young adults who index an orientation towards urban 'street' culture (Anderson 1999:66).

Q U A N T T A T I E A N A L S IS: VARIATION A D

F R A C T A L R E C R U S I I T Y

\section{Data and methods}

In order to examine the social factors that best predict variation in the HAPPY vowel I report a quantitative analysis of phonetic variation. 674 tokens of HAPPY were analysed from twenty-three female speakers $(M=29.3$; range $=11-48)$. All speakers were recorded in self-selected small groups, ranging between two and four speakers (see Kirkham 2013 for further details on the sample). The data were recorded in a quiet room at Ashton Valley School using Beyerdynamic Opus 55 headset microphones into a laptop computer via a Rolls LiveMix pre-amplifier and Behringer UCA-202 audio interface. Audio files were recorded as $44.1 \mathrm{kHz}$ 16-bit WAV files, downsampled to $22.05 \mathrm{kHz}$ and low-pass filtered at $11 \mathrm{kHz}$.

Acoustic landmarks were labelled for each token of HAPPY based on visual observation of waveforms and wide-band spectrograms. Some previous studies avoid tokens with preceding $/ \mathrm{x} /$ because it typically results in a lowering of F2 in the vowel phase (Fabricius 2002:219), but these tokens are included here and any effects of preceding phonetic context are accounted for in the statistical model. For all tokens not preceded by $/ \mathrm{l} / \mathrm{or} / \mathrm{x} /$, the onset of the labelled vowel was the onset of modal voicing and/or an abrupt rise in the amplitude of F2 on the spectrogram. For preceding liquid contexts, the onset of the labelled interval was the onset of the liquid's F2 steady state, which was defined as the onset of a steady region of F2 on the spectrogram following the previous segment. The offset of all tokens was defined as an abrupt drop in amplitude of F2 in the vowel. There is rarely a reliable acoustic boundary between liquids and vowels (Lawson, Stuart-Smith, Scobbie, Yaeger-Dror \& Maclagan 2011:81), so no attempt was made to place such a boundary, instead using a technique detailed below to capture vowel quality. 
The first two formants (F1, F2) were estimated across the labelled interval in Emu (Harrington 2010) via Linear Predictive Coding using a $45 \mathrm{~ms}$ Blackman window with $10 \mathrm{~ms}$ window shift. Formant values were overlaid on wideband spectrograms and any errors were corrected using Emu's formant correction tool. The entire formant tracks were then imported into $\mathrm{R}$ and the acoustic measurement of F2 minus F1 (F2-F1) was automatically obtained at the time of the peak F2 value during the labelled interval. The F2-F1 measurement was taken at peak F2 as this should represent the target for high front vowels and therefore capture information about vowel quality in liquid-vowel sequences (Harrington 2010:182). Tenser variants are characterised by low F1 and high F2, which contributes to a larger F2-F1, whereas laxer variants are characterised by high F1 and low F2, which contributes to a smaller F2-F1. Prior to calculating F2-F1, formant values were transformed to the Bark scale using the formula in Traunmüller (1990) in order to better model human auditory processing. Additional normalisation was not carried out because the F2-F1 measurement already represents a kind of normalisation, as it captures the relationship between formants as opposed to raw values.

In order to test the extent to which different social and linguistic factors predict variation in HAPPY realisation, linear mixed-effects regression models were fitted to the F2-F1 at peak F2 values using a general-to-specific modelling procedure (Baayen 2008:186-88). All $p$-values were obtained using Markov Chain Monte Carlo simulations, as recommended by Baayen (2008:396), and the threshold for statistical significance was set at $\alpha=.05$. Predictor variables included social factors (community of practice, ethnicity, first language, level of deprivation), linguistic factors (preceding context, following context, vowel in previous syllable, position in intonation phrase, presence of nuclear pitch accent, number of syllables in word, word class, word rhythm, duration of vowel or liquid + vowel interval), and interactions between the social and linguistic factors. Interactions between social factors were also included where possible. Speaker and lexical item were included as random intercepts. 'Word rhythm' refers to whether the word has a 'shortlong' rhythm (a short vowel followed by one consonant and the HAPPY vowel, e.g. city) or an 'equal-equal' rhythm (a long vowel followed by any number of consonants and the HAPPY vowel, for example, really; or a short vowel followed by more than one consonant and the HAPPY vowel, e.g. country). Previous work finds that tenser variants occur in 'equal-equal' words (Local 1986; Watts 2006). Vowel in the previous syllable has also been found to influence HAPPY realisation as an instance of vowel-to-vowel coarticulation, with tenser realisations occurring when the vowel in the previous syllable is [i] (Flynn 2007), and laxer realisations when the vowel in the previous syllable is $[\varepsilon]$ (Watts 2006).

\section{Results}

The final regression model for the female speakers' use of HAPPY is summarised in Table 2. The only social factor that is statistically significant is community of 
TABLE 2. Final linear mixed-effects regression model for the HAPPY F2-F1 at peak F2 (Bark) data. The intercept represents Rebellious girls producing HAPPY with a preceding anterior plosive in a nonnuclear-accented syllable. Random intercepts are speaker and lexical item.

\begin{tabular}{lrrrr}
\hline \hline & $\boldsymbol{\beta}$ & $\boldsymbol{S E}$ & $\mathbf{9 5 \%} \mathbf{C I}$ & \multicolumn{1}{c}{$\boldsymbol{p}$} \\
\hline Intercept & 10.24 & 0.25 & $9.77,10.72$ & $<.001$ \\
Community of practice & & & & \\
Ashton girls & 0.89 & 0.38 & $0.18,1.63$ & .017 \\
$\begin{array}{l}\text { Twilight girls } \\
\text { Parkdale girls }\end{array}$ & 0.76 & 0.37 & $0.07,1.48$ & .032 \\
Preceding context & -0.68 & 0.37 & $-1.36,0.04$ & .063 \\
/1/ & & & & \\
/.I/ & -1.08 & 0.16 & $-1.37,-0.79$ & $<.001$ \\
Nuclear accent & -0.93 & 0.20 & $-1.30,-0.55$ & $<.001$ \\
Yes & & & & \\
Community of practice * preceding /I/ & -0.29 & 0.13 & $-0.55,-0.03$ & .031 \\
Twilight girls & & & & \\
Community of practice * nuclear accented syllable & & & & \\
Parkdale girls & -1.26 & 0.30 & $-1.87,-0.69$ & $<.001$ \\
\hline \hline
\end{tabular}

practice, with the Ashton and Twilight girls both producing HAPPY with higher F2F1 values than the Rebellious girls. This suggests that these two groups produce acoustically tenser realisations of this vowel. Figure 1 shows that the Parkdale girls produce the HAPPY vowel with the lowest F2-F1 values, but they are not significantly different from the Rebellious girls in the statistical model, perhaps due to the large number of outliers for the Rebellious girls. This points towards a pattern whereby the two pro-school CofPs produce tenser realisations (Ashton and Twilight girls) and the two anti-school CofPs produce laxer realisations (Rebellious and Parkdale girls). Ethnicity, level of deprivation, and first language are not significant predictors of variation in HAPPY realisation for the girls. A separate model carried out only on the bilingual speakers found no significant effect of amount of daily heritage language usage, nor amount of heritage language spoken to either parent. This suggests that HAPPY realisation is predicted by community of practice membership, but not by other social factors, such as ethnicity, level of deprivation, or heritage language usage. This is not to say these factors are completely irrelevant, but instead suggests that communities of practice may better represent the site at which these factors intersect with each other.

As predicted, HAPPY has lower F2-F1 when preceded by $/ \mathrm{l} / \mathrm{or} / \mathrm{I} /$ (see Stevens 1998:534, 553) and also when it occurs in a nuclear accented syllable. The interaction between CofP and nuclear accent, however, suggests that it is the Parkdale girls who are causing this main effect, evidenced by their substantially lower F2-F1 values in nuclear accented syllables. Another important result is that the Twilight girls produce higher F2-F1 values in preceding /1/ contexts, which contrasts with 


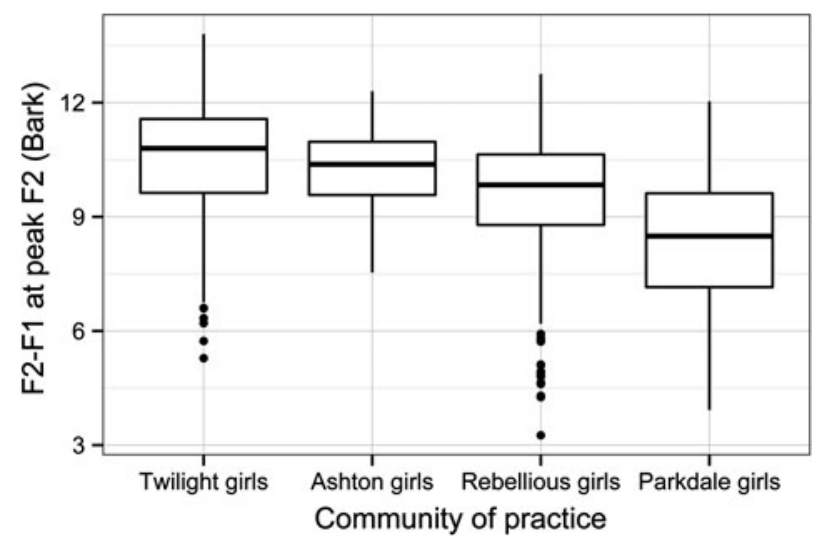

FIGURE 1. Boxplot of F2-F1 at peak F2 values in the HAPPY vowel for the four female communities of practice. Note that the plot does not take into account phonetic context effects on the acoustic values.

the main effect in Table 2 in which /1/ lowers F2-F1. A large proportion of the HAPPY tokens are preceded by $/ 1 /(55.9 \%, \mathrm{~N}=377)$ and one likely explanation for this result is sociophonetic variation in /l/ within Sheffield. White British speakers of Yorkshire English generally produce dark $/ 1 / \mathrm{s}$ in all positions, which is manifested as lower F2-F1 values during /1/ and the surrounding vowels (Carter \& Local 2007). Pakistani speakers of British English, however, are more likely to produce clearer /l/s than their ethnically White British peers in the same geographical location (Heselwood \& McChrystal 2000; Stuart-Smith, Timmins, \& Alam 2011; Kirkham \& Wormald 2015), which means that their ///s may not influence the surrounding vowels in exactly the same way.

In order to test whether the Twilight girls produce acoustically clearer $/ 1 / \mathrm{s}$, a mixed-effects linear regression model was fitted to the F2-F1 data at the 20\% point of the labelled interval. Visual observation of spectrograms determined that this point adequately represents the quality of the $/ 1 /$ in preceding $/ 1 /$ contexts. Predictors in the model are the same as those described for the F2-F1 at peak F2 model. An interaction between CofP and preceding context shows that the Twilight girls have significantly higher $\mathrm{F} 2-\mathrm{F} 1$ at $20 \%$ when HAPPY is preceded by $/ \mathrm{l} /: \beta=1.38$, $S E=0.28,95 \%$ CI $(0.86,1.92), p<.001$. This interaction is not significant for any other social factors and confirms the clearer quality of /l/ for the Twilight girls in these data. These clearer /1/s are likely to represent acquisition of a contact variety that is influenced by the girls' heritage languages, Panjabi and Somali, which are described as having clear $/ 1 / \mathrm{s}$ in all contexts (Mahboob \& Ahmar 2004:1011). Therefore, the effect of HAPPY being tenser when preceded by /l/ for this group may partly represent a coarticulatory effect, with vowels following clearer $/ 1 / \mathrm{s}$ having higher $\mathrm{F} 2-\mathrm{F} 1$ values than those following darker $/ 1 / \mathrm{s}$ (Carter \& Local 2007:194-95). While the origin of this variation may be the Twilight girls' 
heritage languages, neither ethnicity nor first language are significant predictors in the model; instead, community of practice appears to better capture the intersection between heritage language background and social practices.

In summary, the main finding of the quantitative analysis is a pro-school versus anti-school split in HAPPY realisation amongst the girls, with the pro-school Ashton and Twilight girls producing tenser realisations (higher F2-F1) and the anti-school Rebellious and Parkdale girls producing laxer realisations (lower F2-F1). The Twilight girls also produce very clear realisations of $/ \mathrm{l} /$ in words with - $l y$ suffixes, which suggests a further axis of variation within the pro-school girls. Community of practice is the only significant social predictor of phonetic variation, which suggests that the importance of categories such as ethnicity and level of deprivation may reside in how they structure social practice rather than as independent explanatory variables.

\section{Discussion}

These results show that lax realisations of HAPPY are used by the anti-school CofPs - the Rebellious and Parkdale girls - but it seems unlikely that purely socioeconomic conceptions of class explain these results. For example, half of the Rebellious girls are from neighbourhoods that are more affluent than average and half are from neighbourhoods that are less affluent than average (see Table 1). The socioeconomic measure used here (level of neighbourhood deprivation) is also not a significant predictor of HAPPY variation. Instead, it is worth looking towards what social class might mean more locally within the context of the school. Recent sociolinguistic research suggests that individuals may exploit connections between ideologically related meanings of a variant in order to use variation for community-specific ends (Eckert 2008b). To this end, I propose that the patterns in these data represent an ideological restructuring of citywide associations (socioeconomic class) in terms of the local social dynamics of the school (school orientation). This represents an instance of fractal recursivity, which involves 'the projection of an opposition, salient at some level of relationship, onto some other level' (Irvine \& Gal 2000:38). In this case, a binary conception of social class recurs at other levels of social structure, setting up a dichotomy that includes oppositions such as working-class/middle-class, anti-school/pro-school, nonstandard/standard, and so on. The cultural and ideological dimension of this opposition is what is important here because, while the Rebellious and Parkdale girls may orient towards ideologically working-class social practices, not all of the girls would be considered socioeconomically working class (see also Eckert 2000).

In summary, this analysis shows a robust difference between pro-school and anti-school CofPs in HAPPY realisation, which may represent a restructuring of macro-level class associations in terms of local school dynamics. The following section takes up this argument in more detail by analysing further ethnographic detail and the discourse-identity work that surrounds acoustically extreme realisations of HAPPY. In particular, I focus on how the above school-level meanings can be 
interpreted in terms of distinctive CofP styles, which may give rise to subtly different meanings of HAPPY variation. I argue that this kind of indexical reanalysis is partly a consequence of how class and ethnicity intersect within distinctive community of practice styles.

\section{SOCIAL MEANING AND INTERSECTION A L ITY}

\section{Lax HAPPY and anti-school styles}

In this section I explore how lax variants of HAPPY may take on subtly different meanings within the styles of the Parkdale and Rebellious girls. Earlier, I pointed out that the main ethnographic distinction between these two CofPs was the nature of their anti-school attitude: the Parkdale girls rejected school outright and were completely disengaged from lessons, whereas the Rebellious girls wished to renegotiate their relationship with school authority by invoking discourses of reciprocal 'respect'. The two CofPs also differ in how they orient towards notions of 'localness' (e.g. Hall-Lew 2009; Wagner 2013). For example, the Rebellious girls were from socially mixed backgrounds and formed a group identity around a more general 'street' orientation. In contrast, the Parkdale girls emphasised their connection to traditionally (and mainly White) working-class neighbourhoods and were more likely to have access to these discourses through long-established White or White \& Black Caribbean working-class family networks in the city. For example, in extract (2) Kasey and Claire of the Parkdale girls engage in an episode of metalinguistic discourse about the Sheffield accent. They discuss particularly marked local pronunciations and explain when they would use them in their own speech. ${ }^{2}$

(2)

1 Claire: like my mum says things like water *['wa.?ə]

2 [instead of water?]

3 Kasey: [ yeah water, ] *['wa.tə]

4 h- heard, *['i.jəd]

5 again, *[ə.'ge.jãn]

$6 \quad$ and things like that ((laughs))

7 Claire: [((laughs))]

8 Kasey: [ and like ] stupid little things,

9 Sam: do you- do you say things like that?

10 Kasey: yeah sometimes,

11 like if I'm on a roll I say it but,

12 I don't mean to.

13 it just like,

$14 \quad$ comes out naturally, $\quad *$ [natıətë]

15 ((laughs))

16 Claire: like the accent's kind of like dying out now. 
In lines 1-5 Claire and Kasey discuss what they see as typical Sheffield pronunciations of words such as water, heard, and again. Kasey asserts that she uses such stereotyped pronunciations "if I'm on a roll" (line 11), which could represent an appeal to unselfconscious speech or simply being emotionally engaged in a particular discussion. This represents what Bucholtz \& Hall (2004:498) call authentication, 'the construction of a true or veridical identity', which is reinforced through a number of additional strategies. For example, Claire acknowledges that the local variety is "dying out" (line 16), thus essentialising the variety in terms of a small group of presumably older speakers. They implicitly position themselves as not necessarily speakers of this variety, given that they presumably belong to the "new generation" (line 17), but Kasey nonetheless rejects the idea that she's trying to speak in a particular way. For instance, she positions her accent as something that "comes out naturally" [natıəte] (line 14), which coincides with a hyper lax realisation of the HAPPY vowel. In fact, aside from Polly's deliberately stylised token in extract (1), Kasey's production of HAPPY in naturally (line 14) is the acoustically laxest token produced by any female speaker, with a F2-F1 value of 3.92 Bark (the mean value for female speakers is 9.64). While a single example could represent a phonetic context effect, similar tokens occur in similar discourse contexts, such as expressing positive attitudes towards the Sheffield accent and about local youth clubs being shut down due to government cuts (Kirkham 2013:211). Previous research finds that phonetically extreme tokens may be strong indicators of social meaning (Podesva 2011a:254), which suggests that Kasey's use of lax HAPPY here may be strongly tied to notions of locality, history, and the construction of 'authentic' speech styles.

As a point of comparison, extract (3) features an episode of metalinguistic discourse about Sheffield accents by Leila and Saliha, who are core members of the Rebellious girls.

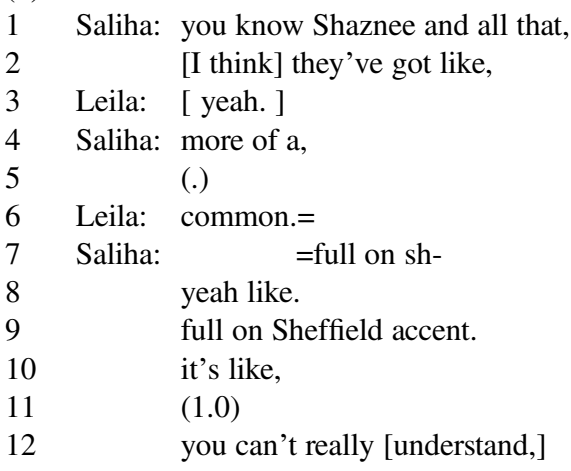




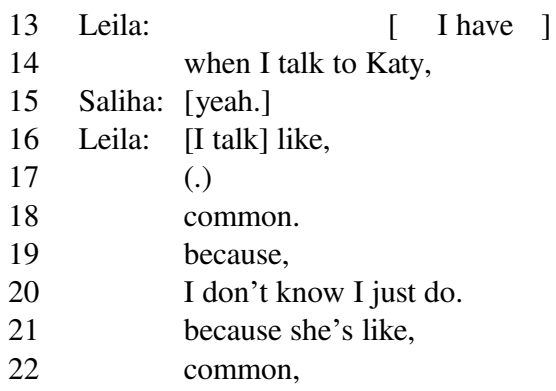

In extract (3), Leila makes a claim to have the kind of "full on Sheffield accent" that Saliha describes in line 9, but only when she talks to her friend, Katy. In doing so, Leila invokes external sources for her use of particular accent features, as opposed to it just coming out "naturally" (see Kasey in extract (2)). Leila then goes on to discursively position her and Katy's linguistic behaviour as "common". Like the term chav in extract (1), the word common was often used to describe negatively stereotyped behaviours associated with (predominantly White British) working-class adolescents at the school, such as misbehaviour and hanging around on the streets. This extract also features a token of the HAPPY vowel, which occurs in the name 'Katy' (line 14; which is a pseudonym for a phonetically similar name). Similar to Kasey's token in extract (2), this token has a very low F2-F1 value of 4.80 Bark (the mean value for female speakers is 9.64), which could similarly suggest a relationship between stance and phonetic variation.

It is important to stress that Kasey and Leila do vary in their production of HAPPY, which is necessary for inferring that the link between stance and acoustically extreme tokens is meaningful. Kasey has a F2-F1 range of 7.6 Bark (3.92-11.52; $M=8.37, S D=2.02)$ and Leila has a F2-F1 range of 7.11 Bark (4.26-11.37; $M=8.42, S D=2.74$ ), both of which are higher than but still comparable to their respective communities of practice (Parkdale girls mean range $=6.21$ Bark; Rebellious girls mean range $=5.99$ Bark). While it is not possible to include discourse extracts on the full range of HAPPY realisations for each speaker, it is notable that the discourse activities surrounding acoustically lax tokens do not occur with acoustically tenser tokens. For example, one of Kasey's few tokens that is acoustically tense occurs in an episode in which she praises a teacher for seeming to care about the students: "I think he wants everybody to do well". It was a very rare event for any of the Parkdale girls to praise a teacher and the token of HAPPY in everybody has a F2-F1 value of 11.47 Bark, which is considerably higher than Kasey's mean of 8.37 Bark. It was not possible to directly compare identical phonetic contexts in many cases like this, because there was often a relationship between stance and lexical choice in tokens of HAPPY. However, this analysis supports the overall relationship between stance and acoustic realisation, which appears to hold at both extremes of the acoustic continuum. 
These two brief extracts suggest that extremely lax tokens of HAPPY do not always occur around overtly 'anti-school' stances, but can also feature in metalinguistic discourse that involves taking a stance towards particular styles of speech. Leila attributes being 'common' to Katy (a White British speaker), which constructs this overtly classed speech style as something that she can put on, rather than as an inseparable part of herself. The idea of language use being influenced by the peer group and particularly 'the streets' was prevalent amongst the Rebellious girls, which may reflect Leila's engagement in this discourse here. By contrast, the Parkdale girls' acquisition of the lax variant may be via long-standing family networks in Sheffield. These potentially different contexts of acquisition and usage may relate to how ethnicity and class intersect in structuring social relations in the school. All of the Parkdale girls are White or White \& Black Caribbean (third generation or later), whereas the Rebellious girls are more mixed, including White and White \& Black Caribbean girls, but also second-generation Pakistani and Bangladeshi girls. All of the Parkdale girls are from neighbourhoods that have average or below average levels of deprivation for city, whereas only half of the Rebellious girls are. Accordingly, the Rebellious girls construe being 'common' as a quality that they can embody, with the group's relative socioeconomic diversity allowing them to play with class ideologies as a stylistic resource. In contrast, the Parkdale girls engage in a different discourse pertaining to a history of local speech and construct identifiably regional speech styles as inherent parts of their identity.

It would be an oversimplification to propose that lax HAPPY means $x$ for one group and $y$ for another, but this analysis does point towards potentially variable associations within different CofP styles. If we accept that phonetic features accrue meanings through their use in particular stances (Kiesling 2009; Podesva 2011a), then the Parkdale girls appear to use lax HAPPY as a part of a set of social practices that emphasise their authentically White and White \& Black Caribbean working-class backgrounds, whereas the Rebellious girls use it as part of an urban-oriented street style. While the classed communitylevel associations of lax HAPPY are at least latent in each case, the specific meanings of HAPPY appear to be contingent upon the different styles of the CofPs who use it.

\section{Tense HAPPY and pro-school styles}

The quantitative analysis suggested that the 'middle-class' citywide associations of tense HAPPY are ideologically reinterpreted as 'pro-school' within Ashton Valley School. It is also possible, however, that tense HAPPY has different meanings in the different styles of the Ashton and Twilight girls, due to how class and ethnicity intersect with social practice. To illustrate some of the differences between the two groups, extract (4) features two of the central members of the Ashton girls, Toni and Nikki, using a series of very tense tokens of HAPPY. 


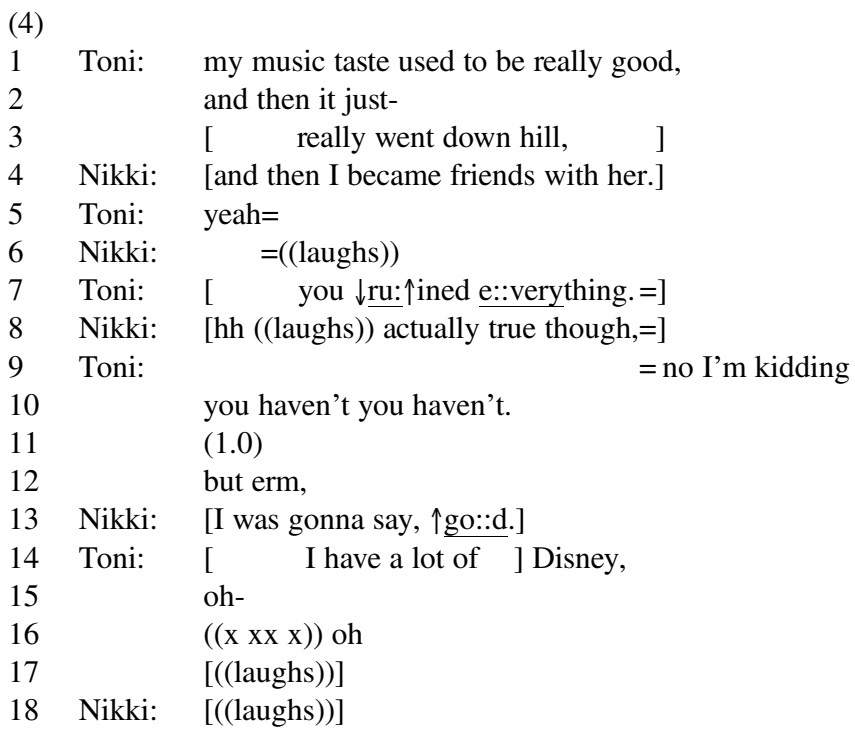

In lines 1-3, Toni states how her music taste "used to be really good", which sets up a contrast between her current self and a projected former self. The tactic of attributing good musical taste to her former self could represent compliance with what Leech (1983:132) terms the 'modesty maxim'. This comprises 'minimise praise of self' and 'maximise dispraise of self' and here we see Toni engaged in dispraise of herself, positioning her current self as uncool in contrast to how her music taste "used to be". Nikki collaborates in this positioning, implying that she negatively influenced Toni's music taste (line 4). One interpretation of this is that Toni is actually making a claim to coolness in the present, but by attributing this to a projected former self she avoids violating the modesty maxim. The Ashton girls regularly constructed similar self-critical evaluative stances when admitting their consumption of cultural phenomena that they considered age-inappropriate or uncool, similar to Toni's claim to have a lot Disney soundtracks (line 14). The notion of something being 'so uncool it's cool' was a defining characteristic of Toni's and Nikki's cultural orientations and they regularly deployed such tactics in constructing a quirky and nerdy, yet cool, persona. Bucholtz (1999) notes similar engagement with avowedly uncool practices and a focus on individuality by nerd girls in a California high school.

There are acoustically tense tokens of HAPPY on line 1 (really -11.67 Bark) and line 14 (Disney - 10.89 Bark). The token on line 8 in actually could not be analysed acoustically because it occurs in overlap, but I would transcribe it as [i]]. This suggests the co-occurrence of tense HAPPY with self-evaluative and self-mocking stances, which appears to facilitate the construction of a quirky and nerdy persona. The intersection between class and ethnicity in this instance is subtle, 
but I would suggest that the Ashton girls' combination of self-critical evaluative stances and consumption of cool/uncool cultural resources evokes discourses surrounding 'cultural omnivores' (Peterson 1992). This refers to a tendency to orient to cultural forms that cut across distinctions between 'high' and 'low' culture, which is ideologically associated with the young and affluent middleclasses (Ollivier 2008). This allows social groups with access to the 'right' cultural mix to assert their superiority via distinction from those with more 'restricted' tastes (Bourdieu 1984).

The Twilight girls' brand of cultural middle-classness was strikingly different from the Ashton girls. They were generally seen as significantly less 'cool' and were from significantly poorer families. To this end, being 'pro-school' means slightly different things for the Ashton and Twilight girls. The Twilight girls' parents are all first-generation immigrants who are highly educated but took up very low-paid jobs after migrating to England. Therefore, the girls are strongly encouraged by their parents to see education as a path towards a 'better life' and greater economic security. The Ashton girls, by contrast, typically have university-educated parents and university is viewed as a default choice, rather than an aspiration. This represents a very different kind of 'middle-class' for each group, as the Ashton girls more strongly orient towards cultural and economic displays of class, whereas the Twilight girls lack access to the same set of cultural and economic resources and instead orient towards displays of educational aspiration.

Both groups' use of tense HAPPY patterns with community-wide trends for young middle-class speakers, but how does simply 'following the trend' fit with the Ashton girls' highly individualistic style? One possibility is the tense variant is reinterpreted through its use in particular stances, which primarily mark the Ashton girls' distinctive nerdy and quirky persona. This is supported by the analysis of extract (4), as well as by fact that the Twilight girls do not appear to differ in their stance-based behaviour when using different kinds of HAPPY realisation. While the Ashton girls further adapt the meaning of tense HAPPY for constructing a quirky and nerdy persona (as in extract (4)), the Twilight girls have little reason to further adapt its meanings due to their lesser focus on cultural displays of classed-behaviour, such as stylistic individuality. This argument is also supported by the Twilight girls' strong desire to want to fit in with the rest of their peer group, given that many of them felt unfairly ostracised and excluded. All of the Twilight girls identified as Muslim and gender ideologies prescribing appropriate behaviour for Muslim girls made them less likely to socialise with boys or engage in prohibited activities such as underage drinking (see also Alam \& Stuart-Smith 2011). To this end, one of the Twilight girls, Izma, claimed that "some people won't just talk to us simply because like, we're Muslims and all that", which was echoed by the other girls on a number of occasions.

A related factor is that the Twilight girls' use of the tense variant may also be influenced by their exposure to the phonetic systems of the local Pakistani and 
Somali communities. Impressionistically, older first-generation Pakistani and Somali speakers in Sheffield produce extremely tense HAPPY vowels, which suggests influence from their L1 (Panjabi or Somali). While there were no substantial acoustic differences between the Twilight and Ashton girls in HAPPY, their productions of this vowel after $/ 1 /$ are tenser than the Ashton girls, which is partly due to the Twilight girls' much clearer /l/s. Given that over half of HAPPY tokens occur after $/ 1 /$, this may contribute towards a percept that the Twilight girls produce a greater proportion of tense tokens overall. The Ashton and Twilight girls' different contexts of acquisition may also explain why we see differences in the stylistic use of HAPPY variation: the Ashton girls have acquired this variant via participation in White middle-class networks, whereas the Twilight girls may have acquired this variant via a contact variety of English spoken in (predominantly Muslim) minority ethnic communities in Sheffield. This points towards a strong influence of how ethnicity interacts with class in producing different conceptions of 'middle-class' amongst pro-school communities of practice.

\section{O N C L U S I O N S}

This article reports differences in the acoustic realisation of the HAPPY vowel amongst female adolescents in a multiethnic secondary school in Sheffield. Proschool girls produce tenser realisations than anti-school girls, which represents an ideological restructuring of citywide class associations in terms of the local social dynamics of the school. In this way, binary oppositions such as 'workingclass' and 'middle-class' recur at a more local level, such as 'anti-school' and 'pro-school'. This relationship between local usage and community-wide trends is likely to be bidirectional: community-wide associations undoubtedly feed into concrete speech events, but the use of HAPPY to index local ethnographic class relations also constitutes and consolidates patterns of variation across the wider community (see Wagner 2013).

My primary claim is that the patterns of variation reported here represent a form of social practice, but that ethnicity and social class intersect in influencing the social practices and ideological orientations of different groups of speakers. Despite the obvious traces of class associations in the pro-/anti-school distinction, straightforward socioeconomic notions of class do not explain the data very well. Most of the Twilight and Parkdale girls would be considered working-class based on the 'level of deprivation' variable, but they occupy opposite ends of the phonetic continuum. In addition to this, ethnicity interacts with a local instantiation of class relations: school orientation. The Ashton girls' use of tense HAPPY appears to be linked to a quirky and nerdy persona, which is interpretable as a kind of individualistic and affluent middle-class-associated social practice. Notably, the Ashton girls' usage of variation patterns with a set of social practices in which the Twilight girls do not have the cultural or economic capital to participate. It may be more necessary for the Ashton girls to adapt the local meanings of HAPPY 
in order to index their distinctiveness from other kinds of middle-class adolescents, given their intense focus on individuality, whereas the Twilight girls' usage may represent a mix of heritage language influence and a fit with existing citywide associations. This shows that similar acoustic variants of HAPPY can clearly occupy different roles within different CofP styles.

The anti-school girls produce very lax realisations of HAPPY in metalinguistic discourse, but subtle differences also emerge within different CofP styles. Kasey of the Parkdale girls evokes notions of authentic speech and traditional local accents, while Leila of the Rebellious girls gestures towards the influence of the peer group and classed notions of being 'common'. The Rebellious girls invoke their engagement in an urban street style, whereas the Parkdale girls' acquisition of the lax variant likely comes from longstanding working-class family networks in Sheffield. These findings can be interpreted in terms of how intersecting meanings of class and ethnicity influence social practice.

At this point, it is worth reflecting on how this analysis can inform accounts of intersectionality. In this article, I have advanced the claim that the locus of sociolinguistic meaning and the effects of intersectionality reside in community of practice-based identities (following Eckert \& McConnell-Ginet 1992). This approach avoids ascribing a 'working-class' or 'Pakistani working-class' identity to individuals and instead traces how the social processes surrounding such categories influence social practice (Moore 2010). Researchers do not have access to the underlying dynamics of social processes, but can only observe their effects, such as how power structures are inscribed in social practices. Therefore, examining how potential intersections structure social practices within communities of practice is a fruitful approach for capturing nuanced dimensions of identity. In doing so, this analysis supports Levon's (2011:81) claim that quantitative identification of linguistic variables combined with qualitative interpretation is a viable method for developing empirical accounts of intersectionality.

In conclusion, this study supports the proposal that the social meanings of linguistic variation exist as variable constellations of ideologically related meanings (Eckert 2008b; Moore \& Podesva 2009). In this case, the social meanings of HAPPY span community-wide correlations (social class), local school categories (school orientation), and CofP-specific stances. Tracing the indexical dynamics of variation in this way may provide insights into broader processes of sociolinguistic change. For example, if other communities in Sheffield increment their own intersectionally classed meanings to the indexical field of the HAPPY vowel, then this may have the effect of further consolidating the macro-level social class associations of HAPPY across the city. It remains to be seen how such phonetic variables and their meanings will change over time, but contextualising such findings in terms of social practice and intersectionality is likely to be an important step in further understanding the contextual dynamics of social categories and sociolinguistic variation. 


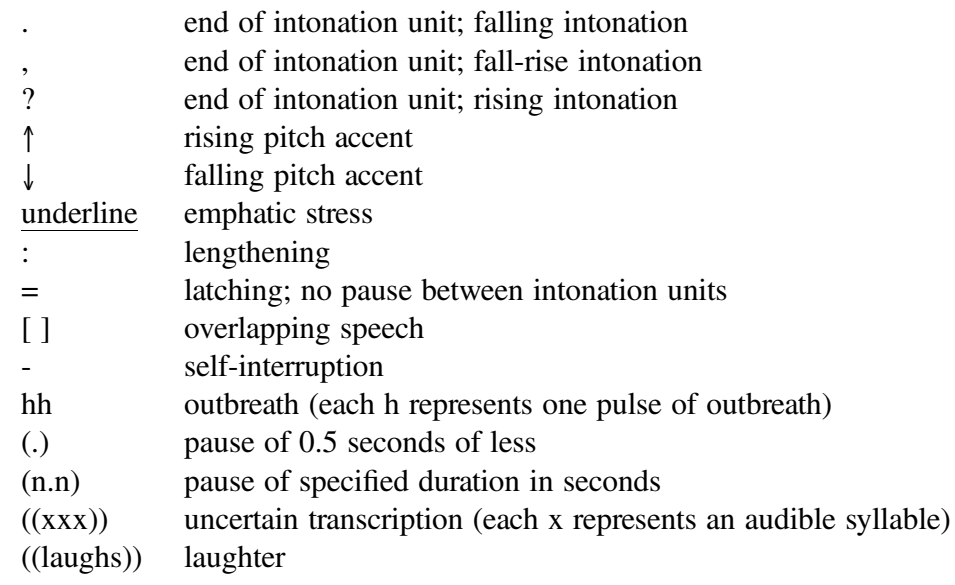

\section{N O T E S}

*Thanks to Emma Moore, Claire Nance, and Gareth Walker for their feedback on previous versions of this article, as well as Jenny Cheshire, Rob Podesva, and an anonymous reviewer for their valuable insights and suggestions for improvement. This work was supported by an Arts \& Humanities Research Council Doctoral Award in Linguistics (grant number AH/I50172X/1).

${ }^{1}$ Transcription conventions (adapted from Bucholtz 2011:xiii) can be found in the appendix. Each line represents a single intonation unit.

${ }^{2}$ Words in bold typeface represent pronunciations that Kasey and Claire position as stereotyped Sheffield accent features, with IPA transcriptions of these words indicated by the * symbol at the end of the relevant line.

\section{R E F E R E N C E S}

Alam, Farhana, \& Jane Stuart-Smith (2011). Identity and ethnicity in /t/ in Glasgow-Pakistani highschool girls. Proceedings of the XVII International Congress of Phonetic Sciences, 216-19.

Anderson, Elijah (1999). Code of the street: Decency, violence, and the moral life of the inner city. New York: W. W. Norton.

Ash, Sharon (2013). Social class. In J. K. Chambers \& Natalie Schilling (eds.), The handbook of language variation and change, 2nd edn., 350-67. Malden, MA: Wiley-Blackwell.

Baayen, Harald (2008). Analyzing linguistic data: A practical introduction to statistics using R. Cambridge: Cambridge University Press.

Barth, Fredrik (1969). Introduction. In Fredrik Barth (ed.), Ethnic groups and boundaries: The social organization of cultural difference, 9-38. Bergen: Universitetsforlaget.

Beal, Joan C. (2004). English dialects in the North of England: Phonology. In Edgar W. Schneider, Kate Burridge, Bernd Kortmann, Rajend Mesthrie, \& Clive Upton (eds.), A handbook of varieties of English 1: Phonology, 113-33. Berlin: Mouton de Gruyter.

Bennett, Joe (2012). 'And what comes out may be a kind of screeching': The stylisation of chavspeak in contemporary Britain. Journal of Sociolinguistics 16(1):5-27.

Benor, Sarah Bunin (2010). Ethnolinguistic repertoire: Shifting the analytic focus in language and ethnicity. Journal of Sociolinguistics 14(2):159-83. 


\section{SAM KIRKHAM}

Block, David (2014). Social class in applied linguistics. London: Routledge.

Bourdieu, Pierre (1977). The economics of linguistic exchanges. Social Science Information 16 (6):645-68.

(1984). Distinction: A social critique of the judgement of taste. London: Routledge.

Bucholtz, Mary (1999). 'Why be normal?': Language and identity practices in a community of nerd girls. Language in Society 28(2):203-23.

(2002). Youth and cultural practice. Annual Review of Anthropology 31:525-52.

(2011). White kids: Language, race and styles of youth identity. Cambridge: Cambridge University Press.

- \& Kira Hall (2004). Theorizing identity in language and sexuality research. Language in Society 33(4):469-515.

Carter, Paul, \& John Local (2007). F2 variation in Newcastle and Leeds English liquid systems. Journal of the International Phonetic Association 37(2):183-99.

Cheshire, Jenny (2002). Sex and gender in variationist research. In J. K. Chambers \& Natalie Schilling-Estes (eds.), The handbook of language variation and change, 423-43. Oxford: Blackwell.

Crenshaw, Kimberlé (1991). Mapping the margins: Intersectionality, identity politics, and violence against women of color. Stanford Law Review 43(6):1241-99.

Docherty, Gerard J., \& Paul Foulkes (1999). Derby and Newcastle: Instrumental phonetics and variationist studies. In Paul Foulkes \& Gerard J. Docherty (eds.), Urban voices: Accent studies in the British Isles, 47-71. London: Arnold.

Dodsworth, Robin (2009). Modeling socioeconomic class in variationist sociolinguistics. Language and Linguistics Compass 3(5):1314-27.

Eckert, Penelope (1989). Jocks and burnouts: Social categories and identity in the high school. New York: Teachers College Press.

(2000). Linguistic variation as social practice: The linguistic construction of identity in Belten High. Oxford: Blackwell.

(2008a). Where do ethnolects stop? International Journal of Bilingualism 12(1-2):25-42.

(2008b). Variation and the indexical field. Journal of Sociolinguistics 12(4):453-76.

(2012). Three waves of variation study: The emergence of meaning in the study of sociolinguistic variation. Annual Review of Anthropology 41:87-100.

- (2014). The problem with binaries: Coding for gender and sexuality. Language and Linguistics Compass 8(11):529-35.

$\longrightarrow, \&$ Sally McConnell-Ginet (1992). Think practically and look locally: Language and gender as community-based practice. Annual Review of Anthropology 21(1):461-90.

Fabricius, Anne H. (2002). Weak vowels in modern RP: An acoustic study of happY-tensing and KIT/ schwa shift. Language Variation and Change 14(2):211-37.

Finnegan, Katie (2005). Phonological variation and change in Sheffield English: An apparent-time study. Sheffield: University of Sheffield, M.A. thesis.

Foucault, Michel (1962). The archaeology of knowledge. London: Tavistock.

Flynn, Nicholas (2007) A sociophonetic comparison of adolescent speech in two areas of Nottingham. Colchester: University of Essex, M.A. thesis.

Halliday, M. A. K. (1990). New ways of meaning: A challenge to applied linguistics. Journal of Applied Linguistics 6:7-36.

Hall-Lew, Lauren (2009). Ethnicity and phonetic variation in a San Francisco neighbourhood. Stanford, CA: Stanford University dissertation.

Harrington, Jonathan (2006). An acoustic analysis of 'happy-tensing' in the Queen's Christmas broadcasts. Journal of Phonetics 34(4):439-57.

(2010). The phonetic analysis of speech corpora. Chichester: Wiley-Blackwell.

Heselwood, Barry, \& Louise McChrystal (2000). Gender, accent features and voicing in Panjabi-English bilingual children. Leeds Working Papers in Linguistics and Phonetics 8:45-70. 


\section{INTERSECTIONALITY AND THE SOCIAL MEANINGS OF VARIATION}

Hughes, Arthur; Peter Trudgill; \& Dominic Watt (2005). English accents and dialects: An introduction to social and regional varieties of English in the British Isles. London: Hodder.

Hymes, Dell (1996). Ethnography, linguistics, narrative inequality: Toward an understanding of voice. London: Taylor \& Francis.

Irvine, Judith T., \& Susan Gal (2000). Language ideology and linguistic differentiation. In Paul V. Kroskrity (ed.), Regimes of language: Ideologies, polities, and identities, 35-84. Santa Fe, NM: School of American Research Press.

Kiesling, Scott F. (2009). Style as stance: Stance as the explanation for patterns of sociolinguistic variation. In Alexandra Jaffe (ed.), Stance: Sociolinguistic perspectives, 171-94. Oxford: Oxford University Press.

Kirkham, Sam (2013). Ethnicity, social practice and phonetic variation in a Sheffield secondary school. Unpublished PhD dissertation. Sheffield: University of Sheffield.

- \& Emma Moore (2013). Adolescence. In J. K. Chambers \& Natalie Schilling (eds.), The handbook of language variation and change, 2nd edn., 277-96. Malden, MA: Wiley-Blackwell.

— \& Jessica Wormald (2015). Acoustic and articulatory variation in British Asian English liquids. Proceedings of the XVIII International Congress of Phonetic Sciences.

Labov, William (1966). The social stratification of English in New York City. Washington, DC: Center for Applied Linguistics.

(1972). Language in the inner city: Studies in the Black English vernacular. Philadelphia: University of Pennsylvania Press.

Lave, Jean, \& Etienne Wenger (1991). Situated learning: Legitimate peripheral participation. Cambridge: Cambridge University Press.

Lawson, Eleanor; Jane Stuart-Smith; James M. Scobbie; Malcah Yaeger-Dror; \& Margaret Maclagan (2011). Liquids. In Marianna Di Paolo \& Malcah Yaeger-Dror (eds.), Sociophonetics: A student's guide, 72-86. London: Routledge.

Lawson, Robert (2011). Patterns of linguistic variation among Glaswegian adolescent males. Journal of Sociolinguistics 15(2):226-55.

Leech, Geoffrey N. (1983). Principles of pragmatics. London: Longman.

Levon, Erez (2011). Teasing apart to bring together: Gender and sexuality in variationist research. American Speech 86(1):69-84.

Local, John (1986). Some rhythm, resonance, and quality variations in urban Tyneside speech. York Papers in Linguistics 12(1):127-34.

Mahboob, Ahmar, \& Nadra Huma Ahmar (2004). Pakistani English: Phonology. In Edgar W. Schneider, Kate Burridge, Bernd Kortmann, Rajend Mesthrie, \& Clive Upton (eds.), A handbook of varieties of English, vol. 1: Phonology, 1003-16. Berlin: Mouton de Gruyter.

Marx, Karl (1852/1972). The eighteenth brumaire of Louis Bonaparte. In Robert C. Tucker (ed.), The Marx-Engels reader, 432-525. New York: W.W. Norton.

McCall, Leslie (2005). The complexity of intersectionality. Signs: Journal of Women in Culture and Society 30(3):1771-1800.

Mendoza-Denton, Norma (2008). Homegirls: Language and cultural practice among Latina youth gangs. Oxford: Wiley-Blackwell.

Milroy, Lesley, \& James Milroy (1992). Social network and social class: Toward an integrated sociolinguistic model. Language in Society 21(1):1-26.

Moore, Emma (2010). Interaction between social category and social practice: Explaining was/were variation. Language Variation and Change 22(3):347-71.

— \& Robert J. Podesva (2009). Style, indexicality, and the social meaning of tag questions. Language in Society 38(4):447-85.

Ollivier, Michèle (2008). Modes of openness to cultural diversity: Humanist, populist, practical, and indifferent. Poetics 36(2-3):120-47.

Oxford English Dictionary Online (2014). Chav, n. Oxford University Press. Online: www.oed.com; accessed April 20, 2015. 


\section{SAM KIRKHAM}

Peterson, Richard A. (1992). Understanding audience segmentation: From elite and mass to omnivore and univore. Poetics 21(4):243-58.

Platt, Lucinda (2005). The intergenerational social mobility of minority ethnic groups. Sociology 39 (3):445-61.

Podesva, Robert J. (2011a). Salience and the social meaning of declarative contours: Three case studies of gay professionals. Journal of English Linguistics 39(3):233-264.

(2011b). The California vowel shift and gay identity. American Speech 86(1):32-51.

Rampton, Ben (2006). Language in late modernity: Interaction in an urban school. Cambridge: Cambridge University Press.

(2010). Social class and sociolinguistics. Applied Linguistics Review 1:1-22.

Rickford, John R. (1986). The need for new approaches to social class in sociolinguistics. Language \& Communication 6(3):215-21.

Rogaly, Ben, \& Becky Taylor (2009). Moving histories of class and community: Identity, place and belonging in contemporary England. Basingstoke: Palgrave.

Rollock, Nicola; David Gillborn; Carol Vincent; \& Stephen J. Ball (2015). The colour of class: The educational strategies of the Black middle classes. London: Routledge.

Sharma, Devyani, \& Lavanya Sankaran (2011). Cognitive forces and social forces in dialect shift: Gradual change in London Asian speech. Language Variation and Change 23(3):399-428.

Snell, Julia (2010). From sociolinguistic variation to socially strategic stylisation. Journal of Sociolinguistics 14(5):630-56.

Stevens, Kenneth N. (1998). Acoustic phonetics. Cambridge, MA: MIT Press.

Stoddart, Jana; Clive Upton; \& J. D. A. Widdowson (1999). Sheffield dialect in the 1990s: Revisiting the concept of NORMs. In Paul Foulkes \& Gerard Docherty (eds.), Urban voices: Accent studies in the British Isles, 72-89. London: Arnold.

Stuart-Smith, Jane; Claire Timmins; \& Farhana Alam (2011). Hybridity and ethnic accents: A sociophonetic analysis of 'Glaswasian'. In Frans Gregersen, Jeffrey K. Parrott, \& Pia Quist (eds.), Language variation: European perspectives III, 43-57. Amsterdam: John Benjamins.

Traunmüller, Hartmut (1990). Analytical expressions for the tonotopic sensory scale. Journal of the Acoustical Society of America 88(1):97-100.

Trudgill, Peter (1974). The social differentiation of English in Norwich. Cambridge: Cambridge University Press.

Wagner, Suzanne Evans (2013). 'We act like girls and we don't act like men': Ethnicity and local language change in a Philadelphia high school. Language in Society 42(4):361-83.

Watts, Emma (2006). Mobility-induced dialect contact: A sociolinguistic investigation of speech variation in Wilmslow, Cheshire. Colchester: University of Essex dissertation.

Wells, John C. (1982). Accents of English, vols. 1-3. Cambridge: Cambridge University Press.

Willis, Paul (1977). Learning to labour: How working class kids get working class jobs. Hampshire: Gower.

(Received 21 August 2014; revision received 20 March 2015; accepted 17 April 2015; final revision received 20 April 2015) 